\title{
In-Flight Calibration of GF-1/WFV Visible Channels Using Rayleigh Scattering
}

\author{
Xingfeng Chen ${ }^{1,2}$, Jin Xing ${ }^{3}$, Li Liu ${ }^{4}$, Zhengqiang $\mathrm{Li}^{1, *}$, Xiaodong Mei ${ }^{1,5, *}$, Qiaoyan Fu ${ }^{4}$, \\ Yisong Xie ${ }^{1}$, Bangyu Ge ${ }^{1}$, Kaitao $\mathrm{Li}^{1}$ and Hua $\mathrm{Xu}^{1}$
}

1 State Environmental Protection Key Laboratory of Satellite Remote Sensing Applications, State Key Laboratory of Remote Sensing Science, Institute of Remote Sensing and Digital Earth, Chinese Academy of Science, Beijing 100101, China; chenxf@radi.ac.cn (X.C.); xieys@radi.ac.cn (Y.X.); geby2015@163.com (B.G.); likaitao2006@sina.com (K.L.); xuhua@radi.ac.cn (H.X.)

2 Key Laboratory of Optical Calibration and Characterization, Chinese Academy of Sciences, Hefei 230031, China

3 Earth Observation Program Center, China National Space Administration, Beijing 100101, China; tonny101579@aliyun.com

4 China Centre for Resources Satellite Data and Application, Beijing 100094, China; liulicugb@126.com (L.L.); fuqiaoyan_2007@126.com (Q.F.)

5 College of Resources and Environment, University of Chinese Academy of Sciences, Beijing 100190, China

* Correspondence: lizq@radi.ac.cn (Z.L.); thymay@foxmail.com (X.M.); Tel.: +86-10-64857437 (Z.L.); +86-10-88256365 (X.M.)

Academic Editors: Alexander A. Kokhanovsky and Prasad Thenkabail

Received: 8 January 2017; Accepted: 19 May 2017; Published: 23 May 2017

\begin{abstract}
China is planning to launch more and more optical remote-sensing satellites with high spatial resolution and multistep gains. Field calibration, the current operational method of satellite in-flight radiometric calibration, still does not have enough capacity to meet these demands. Gaofen-1 (GF-1), as the first satellite of the Chinese High-resolution Earth Observation System, has been specially arranged to obtain 22 images over clean ocean areas using the Wide Field Viewing camera. Following this, Rayleigh scattering calibration was carried out for the visible channels with these images after the appropriate data processing steps. To guarantee a high calibration precision, uncertainty was analyzed in advance taking into account ozone, aerosol optical depth (AOD), seawater salinity, chlorophyll concentration, wind speed and solar zenith angle. AOD and wind speed were found to be the biggest error sources, which were also closely coupled to the solar zenith angle. Therefore, the best sample data for Rayleigh scattering calibration were selected at the following solar zenith angle of $19-22^{\circ}$ and wind speed of $5-13 \mathrm{~m} / \mathrm{s}$ to reduce the reflection contributed by the water surface. The total Rayleigh scattering calibration uncertainties of visible bands are $2.44 \%$ (blue), $3.86 \%$ (green), and $4.63 \%$ (red) respectively. Compared with the recent field calibration results, the errors are $-1.69 \%$ (blue), $1.83 \%$ (green), and $-0.79 \%$ (red). Therefore, the Rayleigh scattering calibration can become an operational in-flight calibration method for the high spatial resolution satellites.
\end{abstract}

Keywords: Rayleigh scattering; Gaofen-1 satellite (GF-1); absolute radiometric calibration; uncertainty analysis

\section{Introduction}

Gaofen-1 (GF-1), as the first satellite of the Chinese High-resolution Earth Observation System (CHEOS), was successfully launched 26 April 2013. This satellite provides data for land and resources surveys, disaster prevention and other fields. GF-1 has two high spatial resolution cameras and four Wide Field Viewing cameras (GF-1/WFV) [1]. The resolution of the WFV is $16 \mathrm{~m}$, which includes four 
spectral bands. The China Centre for Resource Satellite Data and Application (CRESDA) conducts field calibration experiments every year in the Dun Huang desert site [2].

The annual response changes of optical sensors cannot be ignored, especially at the bands of less than $500 \mathrm{~nm}$ [3]. The GF-1/WFV changed $-1.41 \%$ (blue), $-4.72 \%$ (green), $-9.24 \%$ (red), and $8.78 \%$ (near infrared), according to the calibration coefficients published on the website of CRESDA [4]. To guarantee the accuracy of quantitative application, in-flight calibration should be conducted at a high frequency [5]. GF-1 has no onboard calibration instruments, so vicarious and cross calibration methods should be developed [6,7]. Nowadays, the operational method taken by CRESDA for high spatial resolution satellites uses the Dun Huang desert site as a vicarious optical reference [7].

There exist various methods for in-flight radiometric calibration [8]. Slater et al. [9] calibrated the Thematic Mapper (TM) sensor on Landsat 4 using the White Sands site, which is uniform and flat in a large area. Biggar et al. [10] calibrated two sensors on the Earth Observing 1 (EO-1) satellite, performing many experiments at a variety of sites. Sun et al. [11] calibrated the Medium-Resolution Spectral Imager (MERSI) on the Chinese meteorological satellite FY-3A using the Dun Huang site annually.

With the increase in spatial resolution, optical sensors have multi-level gain and exposure time settings. Therefore, an optical sensor may have multiple calibration coefficients, with these multiple calibrations needing to be completed in a short time. In-flight calibration needs to use easily obtained natural scenes as a vicarious optical reference to improve the calibration efficiency.

Considering that the field calibration experiments need a considerable number of instruments, money and manpower in addition to not being applicable for history data, calibration methods that do not need field measurements were developed, such as cross [12], desert [13], moon [14], cloud [15] and Rayleigh scattering [16] calibration.

The Rayleigh scattering calibration method is developed for the in-flight vicarious calibration in the 443-670 nm wavelength bands using remote-sensing images over a clean ocean. Over the clean ocean area that is far away from the main land, the water and aerosol make only a small contribution to the radiance at the Top of Atmosphere (TOA) in the 443-670 nm wavelength bands, so the TOA signal is mainly contributed from the Rayleigh scattering of gas molecules. The sensor can be calibrated depending on the high precision of Rayleigh scattering radiative calculations.

The Rayleigh scattering calibration method, first proposed by Fraser and Kaufman [17], was used for the Visible Infrared Spin-Scan Radiometers (VISSR) onboard the Geostationary Operational Environmental Satellites (GOES5 and GOES6) with 2\% error. Vermote et al. [18] calibrated the $450 \mathrm{~nm}$ and $550 \mathrm{~nm}$ bands for the Satellite Pour l'Observation de la Terre (SPOT) using Rayleigh scattering with 3\% and 5\% errors. Hagolle et al. [19] calibrated the Polarization and Directionality of the Earth's Reflectances instrument (POLDER), while Briottet et al. applied this method to vegetation [20]. Vermote and Kaufman calibrated the Advanced Very High-Resolution Radiometer (AVHRR) with an uncertainty of $2-3.5 \%$ [21]. Therefore, the Rayleigh scattering calibration has been applied to operational calibration of satellite sensors for its good accuracy.

The GF-1/WFV is calibrated using oceanic images and other supporting data. First, the necessity and research status of Rayleigh scattering calibration for high-resolution satellites are introduced. Second, the materials, principle and the procedure of the Rayleigh scattering calibration for the high spatial resolution GF-1/WFV are introduced. After that, the Rayleigh scattering calibration was performed and the primary results are shown. The rule of data selection is important to ensure high calibration accuracy when the Rayleigh scattering calibration method is applied to a sensor with high spatial resolution. Fourth, as the main part of this paper, the calibration uncertainty is discussed, considering each oceanic or atmospheric parameter using the radiative transfer model, which is named Second Simulation of the Satellite Signal in the Solar Spectrum (6S) [22]. Fifth, the final calibration results are calculated using the selected samples and total uncertainties are given. Finally, according to the uncertainty analysis, some data processing and sample selecting experiences are concluded to guarantee a high accuracy. 


\section{Materials and Methods}

\subsection{GF-1/WFV Sensor Characteristics and Imagery}

GF-1/WFV is composed of four cameras in order to achieve both a large swath $(800 \mathrm{~km})$ and a high spatial resolution $(16 \mathrm{~m})$. The large swath brings a shorter time of global coverage, so the GF-1/WFV is widely used in many quantitative remote-sensing fields. Therefore, the radiometric calibration of GF-1/WFV has become more important. The Rayleigh scattering calibration method can improve the calibration time interval. The GF-1/WFV has a good response range and linearity in observing both dark targets (such as water) and bright targets (such as deserts), so the water objects could also be detected with a high sensitivity and signal-to-noise ratio. GF-1/WFV has the potential to use Rayleigh scattering signals for calibration over ocean.

From September to October 2015, the third camera WFV3 of GF-1/WFV was arranged to obtain a series of remote-sensing images over ocean areas to test the Rayleigh scattering calibration method. The other three WFVs were designed to be the same as WFV3, but there exist radiometric and geometric differences in reality. The specifications of a WFV are shown in Table 1. The spectral response functions are shown in Figure 1.

Table 1. Primary characteristics of the Wide Field Viewing cameras onboard Gaofen-1 satellite (GF-1/WFV).

\begin{tabular}{|c|c|c|c|c|c|c|}
\hline Sensor & $\begin{array}{l}\text { Bands } \\
(\mathrm{nm})\end{array}$ & $\begin{array}{l}\text { Central Wave } \\
\text { Length (nm) }\end{array}$ & $\begin{array}{c}\text { Spatial } \\
\text { Resolution }\end{array}$ & Swath & $\begin{array}{c}\text { View Zenith } \\
\text { Angle }\end{array}$ & $\begin{array}{l}\text { Revisit } \\
\text { Period }\end{array}$ \\
\hline WFV & $\begin{array}{l}450-520 \\
520-590 \\
630-690 \\
770-890\end{array}$ & $\begin{array}{l}484 \\
560 \\
665 \\
800\end{array}$ & $16 \mathrm{~m}$ & $800 \mathrm{~km}$ & $\begin{array}{l}\text { WFV2 and WFV3: } \\
0-24^{\circ} \\
\text { WFV1 and WFV4: } \\
24-40^{\circ}\end{array}$ & 4 days \\
\hline
\end{tabular}

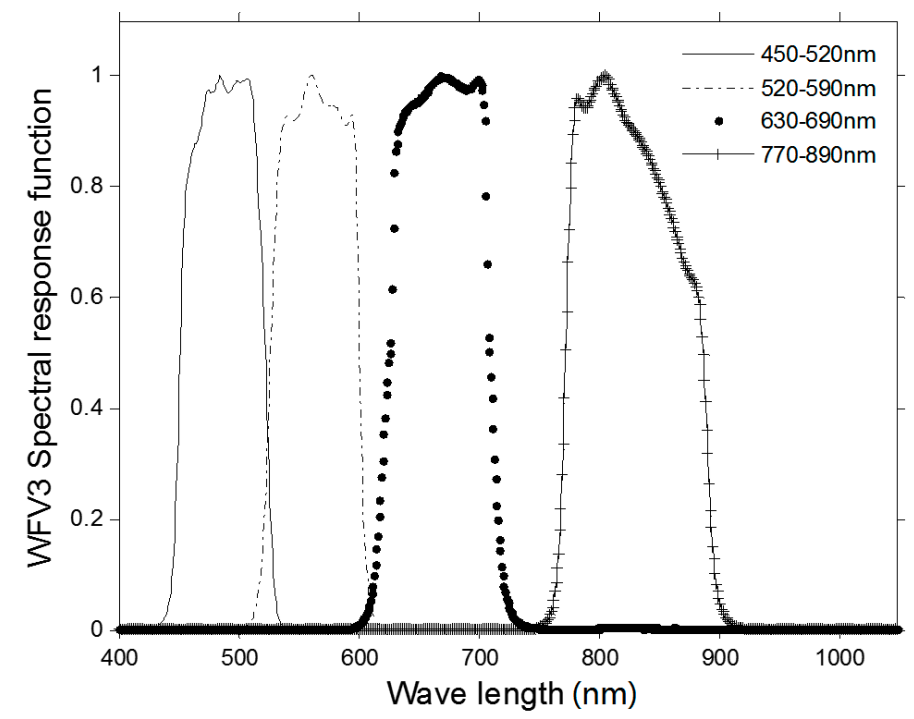

Figure 1. Spectral response functions of the third Wide Field Viewing camera onboard Gaofen-1 satellite (GF-1/WFV3).

\subsection{Atmospheric and Oceanic Parameters}

The atmospheric and oceanic parameters are used to support the radiative transfer model (RTM) calculation as well as to estimate the calibration error. Before calibration calculation, the parameters measured simultaneously to the image should be prepared, including AOD, total ozone amount, seawater salinity, chlorophyll concentration and wind speed. The AOD is obtained from the Moderate 
Resolution Imaging Spectroradiometer (MODIS) Level-2 AOD product (MOD04), which has a spatial resolution of $10 \mathrm{~km} \times 10 \mathrm{~km}$ and an accuracy of $\pm(5 \% \mathrm{AOD}+0.03)$ [23]. The total ozone amount is obtained from the Total Ozone Mapping Spectrometer (TOMS) and Ozone Monitoring Instrument (OMI) daily products with a spatial resolution of $1^{\circ}$ (latitude) $\times 1.25^{\circ}$ (longitude) and an accuracy of $\pm 2 \%$ [24]. The seawater salinity is obtained from National Centers for Environmental Prediction (NCEP) Global Ocean Data Assimilation System (GODAS) with a spatial resolution of $0.33^{\circ} \times 1^{\circ}$ and an accuracy of $\pm 0.2 \%$ [25]. The chlorophyll concentration is given by MODIS-Terra chlorophyll-a concentration data with spatial resolution of $4.63 \mathrm{~km} \times 4.63 \mathrm{~km}$ with an accuracy better than $41 \%$ [26]. The wind speed is available as the European Center of Medium Weather Forecast (ECMWF) ERA-40 product with a spatial resolution of $1^{\circ} \times 1^{\circ}$ and an accuracy of $\pm 2 \mathrm{~m} / \mathrm{s}$ [27]. These data are selected to be synchronized with the satellite images for calibration.

\subsection{Dun Huang Field Calibration Results}

The calibration results released on the CRESDA website were used for validation. The Chinese optical satellite sensors are calibrated using measurements at the Dun Huang desert site. Usually in September and October every year, a comprehensive field experiment is conducted at the Dun Huang site. The surface reflectance can be measured using a spectroradiometer. The aerosol properties are measured using the French CIMEL CE318 automatic sun photometer synchronously with the satellite. The 6S RTM is used to calculate the TOA radiance to calibrate the sensor in the Dun Huang site calibration.

\subsection{Principles and Procedures}

Considering the minor contributions of aerosol scattering, water backscattering, whitecap diffuse reflection, surface specular reflection, gaseous absorption and the biggest contribution to Rayleigh scattering, the TOA radiance over ocean water can be calculated using an RTM [17]. Following this, the calibration coefficient can be given as a relationship between the Digital Number (DN) and the TOA radiance. The DN is the level $1 \mathrm{~A}$ data of GF-1/WFV.

The radiance over a clean ocean received by a satellite sensor [28] is defined as

$$
L=\left(L_{r a y}+L_{a e r}+\left(L_{w}+L_{f}\right) T_{A}+L_{o a}\right) \cdot T_{g}
$$

where $L_{\text {ray }}$ is the Rayleigh scattering contribution of gas molecules; $L_{a e r}$ is the scattering contribution of aerosol particles (when calculate $L_{a e r}$ using $6 \mathrm{~S}$, the aerosol-Rayleigh coupling is also included [22]); $L_{w}$ and $L_{f}$ represent the diffuse contributions of sea water and foam, respectively; $T_{A}$ means the aerosol and Rayleigh transmission; $L_{o a}$ represents the coupling contribution between ocean and atmosphere; and $T_{g}$ is the gaseous transmission. When the atmosphere is clean, the $L$ to which $L_{\text {ray }}$ contributes as much as $90 \%$ [29] can be calculated accurately using a radiative transfer code.

The TOA radiance of band $i$ can be written as

$$
L_{i}=\frac{\int R_{\lambda} L_{i \lambda} d \lambda}{\int R_{\lambda} d \lambda}
$$

where $R_{\lambda}$ is the spectral response of GF-1/WFV (Figure 1) and $L_{i \lambda}$ is the TOA radiance wavelength $\lambda$. Vermote et al. [22] developed the 6S RTM, which improved the computational accuracy for aerosol and Rayleigh scattering compared with the successive order of scattering (SOS) algorithm [30]. The sea surface reflectance can be calculated as a function of the wind speed by the $6 \mathrm{~S}$ model (details in Section 4.5.1). Therefore, $L_{i}$ can be calculated by the $6 \mathrm{~S}$ model using a dataset including spectral response, geometric angles, oceanic and atmospheric parameters, and wind speed.

The radiative response of an optical sensor describes the relationship between $L_{i}$ and $D N_{i}$, which can be defined as

$$
L_{i}=A_{i} \cdot D N_{i}+\text { Offset }_{i}
$$


where $D N_{i}$ is the digital number of band $i$, and the $O f f$ set $_{i}$ is the band-specific additive rescaling bias. The GF-1/WFV level 1A data has been processed with a relative radiometric correction, including deduction of the offset induced by dark current and other factors [31]. In the Dun Huang calibration and the calibration of this paper, we consider $O f f$ set $_{i}=0$. Therefore, the band-specific multiplicative rescaling gain $A_{i}\left(\mathrm{~W} \cdot \mathrm{m}^{-2} \cdot \mathrm{sr}^{-1} \cdot \mu \mathrm{m}^{-1}\right)$ is the only absolute radiative calibration coefficient, which will be calculated by Equations (2) and (3).

According to the Figure 2, the procedures of calibration are as follows:

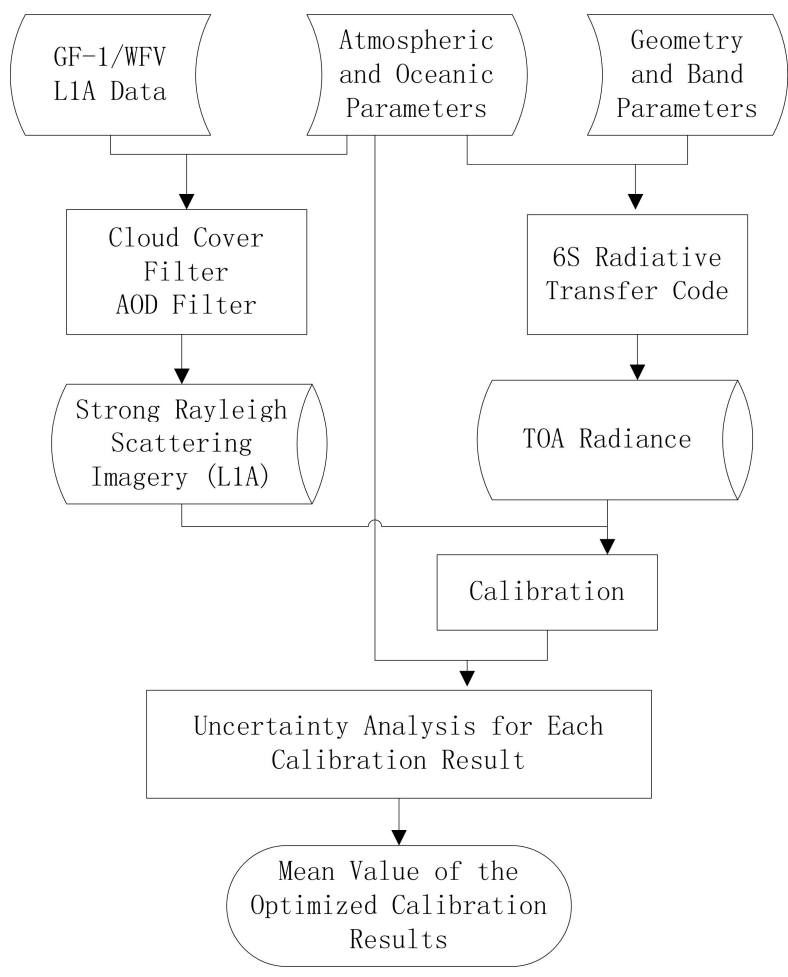

Figure 2. The flow chart of the Rayleigh scattering calibration for the Wide Field Viewing cameras onboard Gaofen-1 satellite (GF-1/WFV).

(1) Obtain images over an ocean area for Rayleigh scattering calibration. As a land resources satellite, GF-1 has obtained seldom ocean images. For the Rayleigh scattering calibration, one of the four WFVs was specially arranged to obtain images over the ocean. The images for Rayleigh scattering calibration should follow the conditions [17] including: (a) case I waters for reducing the total reflection of seawater; (b) clean atmosphere for reducing aerosol scattering; and (c) large solar zenith angle for enhancing atmospheric molecules scattering. According to these conditions, we chose the case I water, which contains little chlorophyll in both spatial and temporal dimensions [32,33]. Figure 3 shows the September-October 2015 mean global distribution map of oceanic chlorophyll. GF-1/WFV obtained 31 images over the square areas shown in Figure 3 from September to October 2015.

(2) Obtain and process the atmospheric and oceanic parameters corresponding to each image. Strictly synchronized observations are difficult to obtain, so the nearest spatial and temporal observations are used instead. We assume that the related parameters have negligible changes within one hour, so the observations introduced in Section 2.2, such as AOD and wind speed, can be used in Rayleigh scattering calibration. The seawater salinity and chlorophyll concentration are mainly affected by precipitation, continental run-off and ocean current. These factors show slowly varying character, so daily data can be used for calibration. The influence of input parameters on the uncertainty analysis is discussed in the analysis part. 


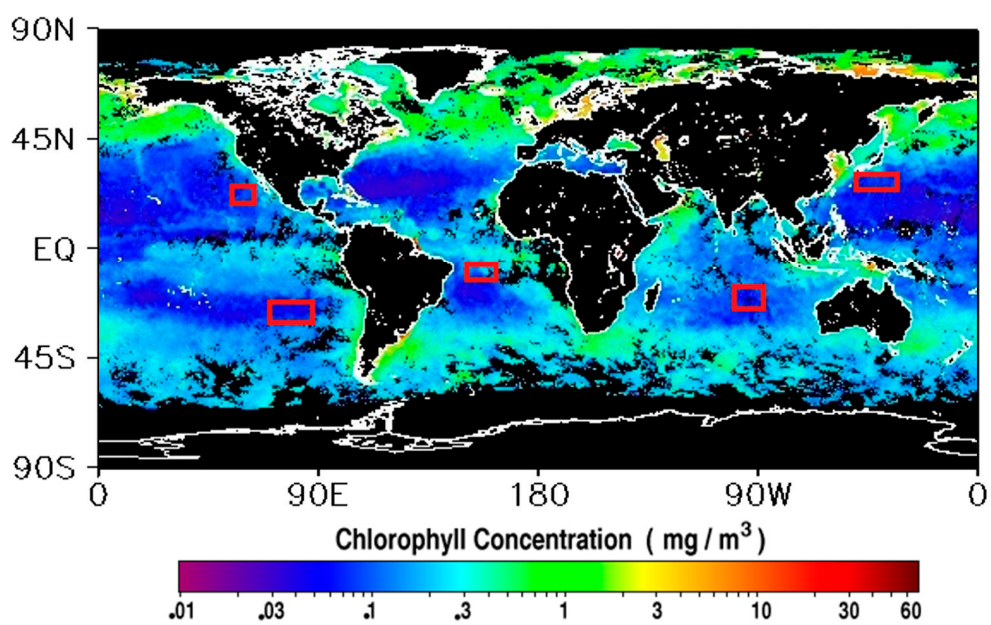

Figure 3. 2015 September-October global chlorophyll concentration (red squares show the target distribution for the Rayleigh scattering calibration, Unit: $\mathrm{mg} / \mathrm{m}^{3}$ ).

(3) Select suitable images considering atmospheric and oceanic parameters. To ensure the atmosphere is "clean", the selecting rules include: (a) the total cloud pixels accounted to no more than $15 \%$ in an image; (b) the cloud areas are not fragmented in an image (from visual inspection); (c) there exist no sun glint in an image (from visual inspection); and (d) the AOD should be smaller than 0.1 at the wavelength of $550 \mathrm{~nm}$. Following this, 22 sample images were selected, which were distributed in five ocean areas (Table 2), including 11 in the Southeast Pacific, 6 in the Northwest Pacific, 2 in the Tropical Eastern Pacific, 2 in the South Indian Ocean and 1 in the Tropical South Atlantic.

Table 2. The solar and viewing geometries as well as wind speed for the 22 samples.

\begin{tabular}{cccccc}
\hline Sample ID & Oceanic Area & $\begin{array}{c}\text { Solar Zenith } \\
\left({ }^{\circ}\right)\end{array}$ & $\begin{array}{c}\text { Viewing } \\
\text { Zenith }\left(^{\circ}\right)\end{array}$ & $\begin{array}{c}\text { Relative } \\
\text { Azimuth }\left({ }^{\circ}\right)\end{array}$ & $\begin{array}{c}\text { Wind Speed } \\
(\mathbf{m} / \mathbf{s})\end{array}$ \\
\hline 1 & & 22.208 & 8.847 & 118.979 & 2.5 \\
2 & & 24.857 & 8.851 & 115.215 & 4 \\
3 & & 26.338 & 8.853 & 113.505 & 4 \\
4 & 33.317 & 9.639 & 156.345 & 3 \\
5 & & 20.055 & 4.795 & 167.002 & 8 \\
6 & Southeast Pacific & 20.499 & 8.843 & 119.304 & 2.5 \\
7 & & 20.353 & 8.841 & 119.721 & 7.5 \\
8 & & 28.984 & 8.854 & 110.279 & 6 \\
9 & & 30.525 & 8.856 & 109.097 & 7.5 \\
10 & & 20.031 & 8.841 & 120.274 & 5 \\
11 & & 19.925 & 8.839 & 120.712 & 12.5 \\
\hline 12 & & 39.394 & 10.734 & 81.76 & 8 \\
13 & & 34.3 & 16.388 & 138.434 & 5 \\
14 & & 34.901 & 8.787 & 113.513 & 4 \\
15 & Northwest Pacific & 35.935 & 15.816 & 105.528 & 7 \\
16 & & 37.831 & 8.78 & 112.186 & 7 \\
17 & & 25.549 & 8.798 & 122.76 & 6.1 \\
\hline 18 & & 22.912 & 8.796 & 124.716 & 2.5 \\
19 & Tropical Eastern Pacific & 20.09 & 8.799 & 120.712 & 2 \\
20 & & 33.998 & 10.816 & 68.908 & 9 \\
21 & South Indian Ocean & 36.986 & 13.37 & 84.942 & 9 \\
\hline
\end{tabular}

All 22 samples were used to complete the Rayleigh scattering calibration. In the discussion chapter of this paper, the optimal samples were selected with calibration uncertainty analysis. 
(4) Process the cloud-free areas in the images. In the images from GF-1/WFV3, the bright and dark slopes of the sea waves are obviously different as shown in Figure 4. In order to ensure the accuracy and stability of Rayleigh scattering calibration, the DN values are averaged twice. Firstly, several cloud-free square areas (CFSA) in the image are selected and extracted to calculate the mean value (MCFSA). We tested different averaged scales of CFSA and at last, the side length is recommended to be $3-5 \mathrm{~km}$ because the averaged value in this scale is stable. Secondly, a number of CFSAs in a limited viewing angle range (VAR, no more than $1^{\circ}$ ) are selected to calculate each MCFSA. Thirdly, in the mean value sequence of MCFSAs, the single MCFSA that has a standard deviation bigger than $1 \%$ is removed. Finally, the rest mean values of MCFSAs are averaged again to get the final DN for calibration. Every parameter used for calibration is averaged to the same size as the calibration area (VAR) in the image.

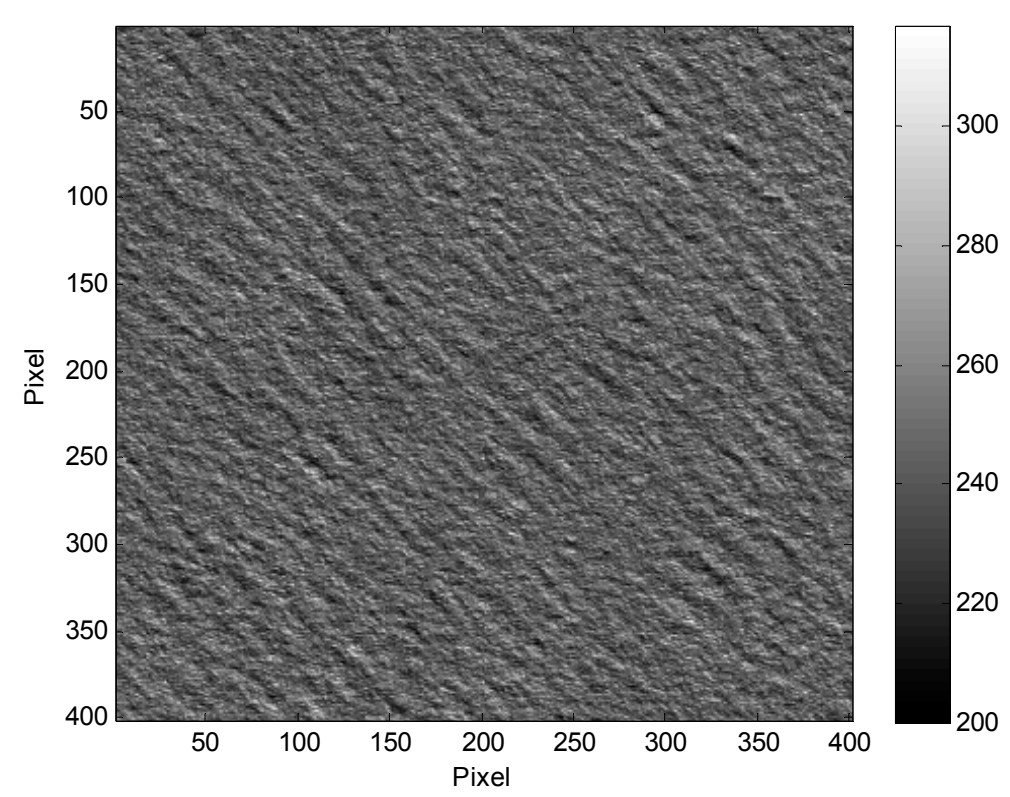

Figure 4. Example of a slope distribution extracted from GF-1/WFV3 level 1A image. The size of one pixel is $16 \mathrm{~m} \times 16 \mathrm{~m}$. The Digital Number $(\mathrm{DN})$ values are between 210 and 307 .

(5) Calculate the radiance and perform calibration. The 6S RTM is used to calculate TOA radiance with the inputs of solar and observing angles (center value in the VAR), month and day of imaging time, atmospheric model, aerosol model, spectral response function, atmospheric and oceanic parameters (mean value of each parameter in the VAR). The imaging time is from the metadata and the geometric conditions, including four angles, are from the geoinformation of GF-1/WFV image. The atmosphere model is selected from the built-in models, according to the geographical position and grabbing season. The aerosol model is set to be "Maritime", which is also provided by the $6 \mathrm{~S}$ model. The atmospheric and oceanic parameters are prepared from the measurements introduced in Section 2.2. The $6 \mathrm{~S}$ can provide TOA radiance with a full input, following instructions in the main code. According to Equation (3), for each sample, the calibration coefficient can be calculated by comparing TOA radiance and the final $\mathrm{DN}$ mean value.

(6) Analyze the uncertainty and obtain the optimal calibration result. Jointly considering the calibration result and the error source, the optimal calibration coefficients are selected. At last, the optimal calibration result is the mean value of the optimal calibration coefficients.

\section{Primary Results of All Samples}

According to the principles and procedure of Rayleigh scattering calibration, the GF-1/WFV3 satellite sensor was calibrated using 22 oceanic images acquired in September and October in 2015. The 
calibration results of the three visible bands at 450-520 nm (blue), 520-590 nm (green), and 630-690 nm (red) are shown in Figure 5. The mean values of 22 calibration coefficients (Table 3) are 0.1755 (blue), 0.1645 (green), and 0.1351 (red), respectively. Corresponding to the mean value, the largest deviation (defined and shown in Table 3) is 0.0117 (blue), 0.0117 (green), and 0.0126 (red) respectively, with the largest deviation ratios being in the range of 6.67-9.33\%. For validation and assessment, the field calibration data are used to compare with the Rayleigh scattering calibration. The CRESDA conducted a field calibration campaign at the Dun Huang desert site in August 2015 for the land resources satellites. The calibration coefficients from this campaign are 0.1779 (blue), 0.1589 (green), and 0.1385 (red) [4]. Thus, the differences between Rayleigh scattering and field calibration are $-0.0024(-1.35 \%)$, $0.0056(3.52 \%)$, and $-0.0034(-2.45 \%)$. The results of the two calibration methods are well consistent in the blue band, with bigger deviations occurring in the green and red bands. This may be caused by the weaker Rayleigh scattering of gas molecules and stronger aerosol scattering interference at the longer wavelength.

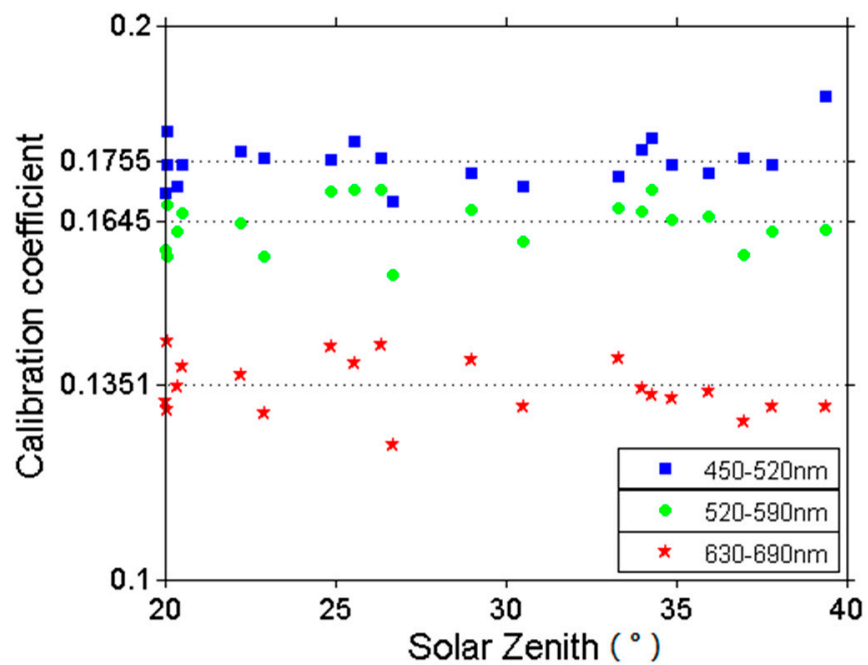

Figure 5. Absolute radiometric calibration coefficients $\left(\mathrm{A}_{\mathrm{i}}\right)$ of 22 samples computed by the Rayleigh scattering method versus solar zenith angle at wavelengths of 450-520 nm (blue), 520-570 nm (green), and $630-690 \mathrm{~nm}$ (red). The mean coefficients for the 3 bands are $0.1755,0.1645$, and 0.1351 , respectively.

Table 3. The assessment for the Rayleigh scattering calibration of GF-1/WFV3 and the comparison with the Dun Huang field calibration.

\begin{tabular}{cccc}
\hline Band & $\mathbf{4 5 0 - 5 2 0} \mathbf{~ n m}$ & $\mathbf{5 2 0 - 5 9 0} \mathbf{n m}$ & $\mathbf{6 3 0 - 6 9 0 ~} \mathbf{n m}$ \\
\hline Averaged calibration coefficients (ACC) & 0.1755 & 0.1645 & 0.1351 \\
Root mean square error & 0.0041 & 0.0046 & 0.0052 \\
Largest deviation (LD) & 0.0117 & 0.0117 & 0.0126 \\
Largest deviation ratio (LDR) * & $6.67 \%$ & $7.11 \%$ & $9.33 \%$ \\
Calibration coefficients of the field calibration & 0.1779 & 0.1589 & 0.1385 \\
Relative deviation between Rayleigh scattering and field calibrations & $-1.35 \%$ & $3.52 \%$ & $-2.45 \%$ \\
\hline
\end{tabular}

${ }^{*} \mathrm{LD}$ is the biggest absolute difference of $A_{i}$ with the mean $A ; L D R=L D / A C C$.

\section{Discussion of Uncertainty Analysis and Sample Selection Rules}

The uncertainty of Rayleigh scattering calibration is dominated by the oceanic and atmospheric parameters. The ozone amount affects the gaseous absorption contribution, while the AOD affects the scattering contribution. Furthermore, the wind speed affects the whitecap and sun glint contributions, while the seawater salinity and chlorophyll concentration affect the water-leaving contributions. 
The calibration uncertainties can be induced by the errors of seawater salinity, chlorophyll concentration, ozone amount, AOD, and wind speed. Through changing one of these parameters and keeping the rest unchanged, the radiance at TOA is recalculated utilizing the $6 \mathrm{~S}$ model. Following this, the new calibration coefficient is recalculated. The uncertainty $\sigma_{i}$ from each parameter of band $i$ is

$$
\sigma_{i}=\frac{A_{i}^{\prime}-A_{i}}{A_{i}}
$$

where $A_{i}$ is the calibration coefficient from the observation input, and $A_{i}^{\prime}$ is the new calibration coefficient from the changed input.

The sea surface is typically a non-Lambertian object, so the uncertainty analysis of the Rayleigh scattering calibration focuses on the geometric conditions. The solar zenith angle is considered together with the analysis for the oceanic and the atmospheric parameters.

\subsection{Uncertainty from Seawater Salinity}

The seawater salinity data is obtained from the Global Ocean Data Assimilation System (GODAS) with a $\pm 0.2 \%$ error [25]. Through adding the maximum error on the seawater salinity, the calibration coefficient is recalculated to analyze the calibration uncertainty. As shown in Table 4, the absolute maximum uncertainties in the 22 calibration samples are $0.002 \%$ (blue), $0.003 \%$ (green), and $0.006 \%$ (red), which are calculated by Equation (4). Consequently, the calibration uncertainty from seawater salinity is very small.

Table 4. Maximum and minimum value of $\sigma_{i}$ induced by seawater salinity measurement errors in the 22 samples.

\begin{tabular}{|c|c|c|c|c|}
\hline Uncertainty & Band & $450-520 \mathrm{~nm}$ & $520-590 \mathrm{~nm}$ & $630-690 \mathrm{~nm}$ \\
\hline Maximum & & $0.002 \%$ & $0.003 \%$ & $0.004 \%$ \\
\hline Minimum & & $-0.002 \%$ & $-0.003 \%$ & $-0.006 \%$ \\
\hline
\end{tabular}

\subsection{Uncertainty from Ozone}

The ozone amount is obtained from the TOMS and OMI daily product with a $\pm 2 \%$ error [24]. Through adding the maximum error on the ozone amount, the calibration coefficient is recalculated to analyze the calibration uncertainty. As shown in Table 5, the absolute maximum uncertainties in the 22 calibration samples are $0.03 \%$ (blue), $0.13 \%$ (green), and $0.08 \%$ (red), which are calculated by Equation (4). The green band has the biggest uncertainty because of the strong absorption of ozone at $500-650 \mathrm{~nm}$. However, the ozone observation generally causes little uncertainty.

Table 5. Maximum and minimum value of $\sigma_{i}$ induced by ozone measurement errors in the 22 samples.

\begin{tabular}{|c|c|c|c|}
\hline $\begin{array}{ll}\text { Uncertainty } & \text { Band }\end{array}$ & $450-520 \mathrm{~nm}$ & $520-590 \mathrm{~nm}$ & $630-690 \mathrm{~nm}$ \\
\hline Maximum & $0.03 \%$ & $0.13 \%$ & $0.08 \%$ \\
\hline Minimum & $-0.02 \%$ & $-0.10 \%$ & $-0.06 \%$ \\
\hline
\end{tabular}

\subsection{Uncertainty from Chlorophyll Concentration}

The chlorophyll in seawater enhances the water-leaving reflectance, so its accuracy affects the calibration uncertainty. The MODIS chlorophyll-a observation is available only with an error reaching to $41 \%$ [26]. Through adding the error from the chlorophyll that amounts to a maximum of $41 \%$, the calibration coefficient is recalculated to analyze calibration uncertainty. As shown in Table 6, the absolute maximum uncertainties in the 22 calibration samples are $0.70 \%$ (blue), $0.84 \%$ (green), and 
$0.29 \%$ (red), which are calculated by Equation (4). An in-situ measurement of chlorophyll would improve the calibration accuracy.

Table 6. Maximum and minimum value of $\sigma_{i}$ induced by chlorophyll concentration measurement errors in the 22 samples.

\begin{tabular}{|c|c|c|c|}
\hline Uncertainty Band & $450-520 \mathrm{~nm}$ & $520-590 \mathrm{~nm}$ & $630-690 \mathrm{~nm}$ \\
\hline Maximum & $0.70 \%$ & $0.58 \%$ & $0.24 \%$ \\
\hline Minimum & $-0.61 \%$ & $-0.84 \%$ & $-0.29 \%$ \\
\hline
\end{tabular}

\subsection{Uncertainty from $A O D$}

In order to reduce the uncertainty from the AOD, the calibration demands a clean atmospheric condition with AOD being no larger than 0.1 at the $550 \mathrm{~nm}$ wavelength. The AOD for calibration are taken from the MODIS product that has the minimum distances to the calibration image in both spatial and temporal dimensions. The error of the MODIS AOD product over the ocean is $\pm(5 \% \mathrm{AOD}$ +0.03 ) [23]. The "Ocean" aerosol model built-in the 6S RTM is chosen to calculate the radiance of the TOA. We added errors on the AOD input to the 6S RTM with a step width of 0.01 until the error reached $\pm(5 \% \mathrm{AOD}+0.03)$, before we recalculated the calibration coefficients. As shown in Figure 6, the calibration uncertainty of every sample increases with a stable slope when the error of AOD is increasing, although these slopes vary widely.

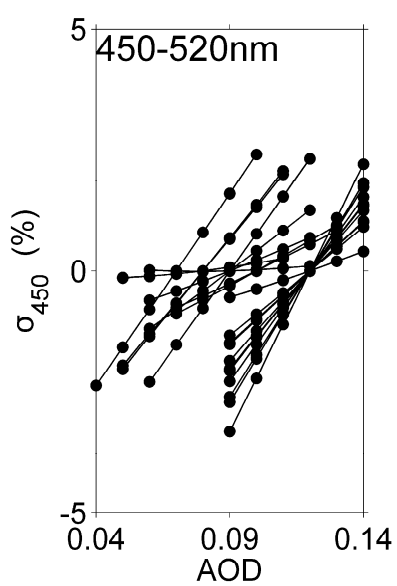

(a)

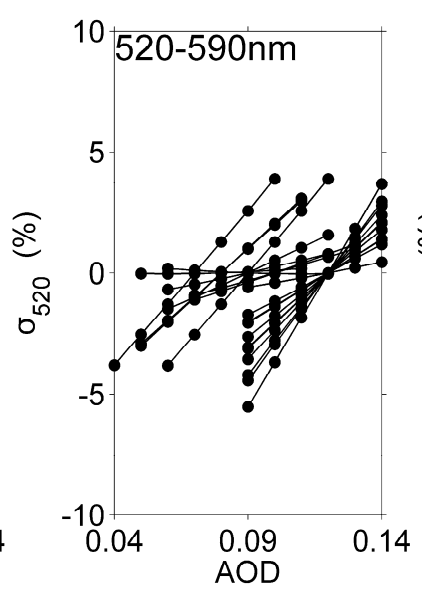

(b)

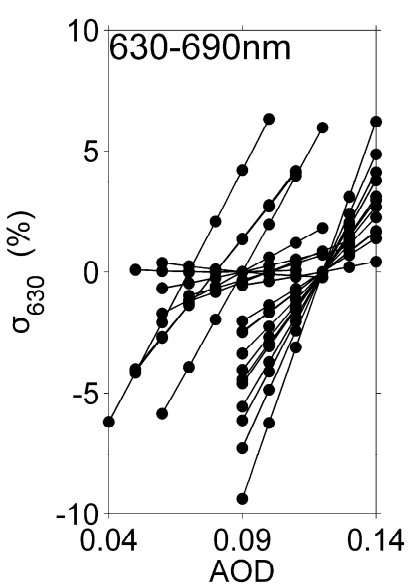

(c)

Figure 6. $\sigma_{i}$ (\%, coefficient uncertainty with Aerosol Optical Depth (AOD) changes in steps of 0.01) of 22 examples varying with AOD at wavelengths of: (a) 450-520 nm; (b) 520-590 nm and (c) 630-690 nm (each line represents $\sigma_{i}$ of one calibration sample with AOD changes).

With a further study, we found that the maximum calibration uncertainty has no stable relationship with the AOD (Figure 7a). When the AOD is added with an error of 0.035 (the maximum error of AODs of all the calibration samples), this results in the maximum calibration uncertainty. Jointly considering the principle of Rayleigh scattering calibration, a small AOD sample should be selected. In Figure 7b, the maximum calibration uncertainty increases with the Solar Zenith (SZ). The SZs of all the 22 samples are in $19-40^{\circ}$. When SZ is between 19 and $22^{\circ}$, the calibration uncertainty is at a minimum, which has values of $1.03 \%$ (blue), $1.28 \%$ (green), and $1.38 \%$ (red). 


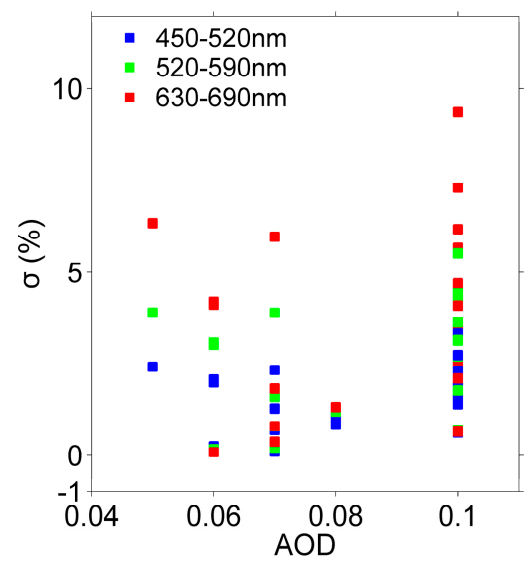

(a)

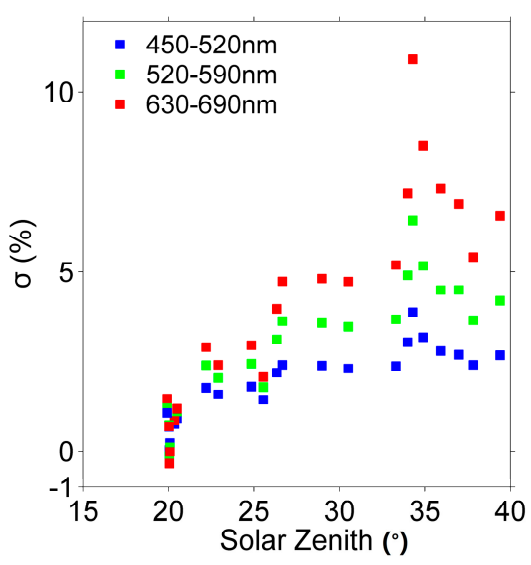

(b)

Figure 7. $\sigma_{i}(\%$, coefficient uncertainty with Aerosol Optical Depth (AOD) changes $\pm(5 \%$ AOD +0.03$))$ of 22 examples versus: (a) AOD and (b) solar zenith angle (marked color represents different bands: 450-520 nm (blue), 520-570 nm (green), and 630-690 nm (red)).

\subsection{Uncertainty from Wind Speed}

Wind speed changes rapidly in both dimensions of time and space, which brings uncertainty through affecting surface reflectance over the ocean. Firstly, in order to study the rules of each sample uncertainty, the sea surface reflectance was simulated using the $6 \mathrm{~S}$ model, jointly considering wind speed $(V)$ and SZ. Secondly, we simulated the uncertainties induced by AOD and SZ in a wide range.

\subsubsection{Sample Uncertainty}

Wind speed is taken from the ERA-40 dataset with an error of $\pm 2 \mathrm{~m} / \mathrm{s}$ [27]. The uncertainty from the wind speed is evaluated by the Bidirectional Reflectance Distribution Function (BRDF). The total BRDF of the sea surface is calculated as follows [34]:

$$
\begin{gathered}
\rho_{o s}\left(\theta_{s}, \theta_{v}, \varphi, \lambda\right)=\rho_{w c}(\lambda)+\{1-W\} \cdot \rho_{g l}\left(\theta_{s}, \theta_{v}, \varphi, \lambda\right)+\left\{1-\rho_{w c}(\lambda)\right\} \cdot \rho_{s w}\left(\theta_{s}, \theta_{v}, \varphi, \lambda\right) \\
W=2.95 \times 10^{-6} V^{3.52}
\end{gathered}
$$

where $\rho_{w c}, \rho_{g l}$ and $\rho_{s w}$ are the reflectance of whitecap, sun glint and water-leaving radiation, respectively; $\lambda$ is the wavelength, so the total BRDF $\rho_{\text {os }}$ gives a spectral reflectance with a certain $\lambda$ range and fixed directions; $V$ is the wind speed; $\theta_{s}$ is the solar zenith; $\theta_{v}$ is the observing zenith; and $\varphi$ is the relative azimuth. $\rho_{s w}$ is influenced by seawater salinity and chlorophyll concentration. $W$ is the relative coverage ratio of the whitecaps, which is a function of $V$ when the surface temperature is bigger than $14{ }^{\circ} \mathrm{C}$ [35]. For the coefficient uncertainty $\sigma_{i}$ due to wind speed errors, $\rho_{w c}$ and $\rho_{s w}$ are negligible $\left(10^{-3}\right.$ in visible bands), compared to the biggest contributor $\rho_{g l}\left(10^{-1}-10^{-2}\right) . \rho_{g l}$ is calculated by the Cox and Munk model [36-38], which is a function of $V$ and geometric conditions (in Equation (7)).

$$
\rho_{g l}\left(\theta_{S}, \theta_{V}, \varphi_{S}, \varphi_{V}\right)=\frac{\pi P\left(Z_{x}^{\prime}, Z_{y}^{\prime}\right) R\left(n, \theta_{S}, \theta_{V}, \varphi_{S}, \varphi_{V}\right)}{4 \cos \left(\theta_{S}\right) \cos \left(\theta_{V}\right) \cos ^{4}(\beta)}
$$

where $P\left(Z_{x}^{\prime}, Z_{y}^{\prime}\right)$, as a function of $V$ [36-38], is the slope distribution expressed by a Gram-Charlier series; $Z_{x}^{\prime}$ and $Z_{y}^{\prime}$ are the two components of the surface slope; $\beta$ is the tilt of the slope facet; and $R\left(n, \theta_{S}, \theta_{V}, \varphi_{S}, \varphi_{V}\right)$ is Fresnel's reflection coefficient (n is the complex refractive index of sea water). Therefore, Equation (5) can be simplified to

$$
\rho_{o s}\left(\theta_{S}, \theta_{v}, \varphi, \lambda\right) \approx\{1-W\} \cdot P\left(Z_{x}^{\prime}, Z_{y}^{\prime}\right) \cdot R\left(n, \theta_{S}, \theta_{V}, \varphi_{S}, \varphi_{V}\right) \cdot \frac{\pi}{4 \cos \left(\theta_{S}\right) \cos \left(\theta_{V}\right) \cos ^{4}(\beta)}
$$


where $R\left(n, \theta_{S}, \theta_{V}, \varphi_{S}, \varphi_{V}\right)$ is related to geometric conditions. Figure 8 shows that Fresnel's reflection coefficient increases with SZ. $\{1-W\} \cdot P\left(Z_{x}^{\prime}, Z_{y}^{\prime}\right)$, as the only term dominated by $V$ changes in Equation (8), can be used to show the calibration uncertainty induced by $V$. With the $\pm 2 \mathrm{~m} / \mathrm{s}$ error of $V$, Figure 9 shows that $\{1-W\} \cdot P\left(Z_{x}^{\prime}, Z_{y}^{\prime}\right)$ introduces little error, when $V$ is larger than $5 \mathrm{~m} / \mathrm{s}$ for all the samples.

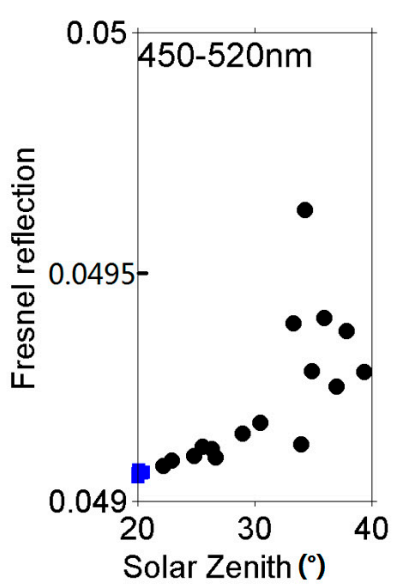

(a)

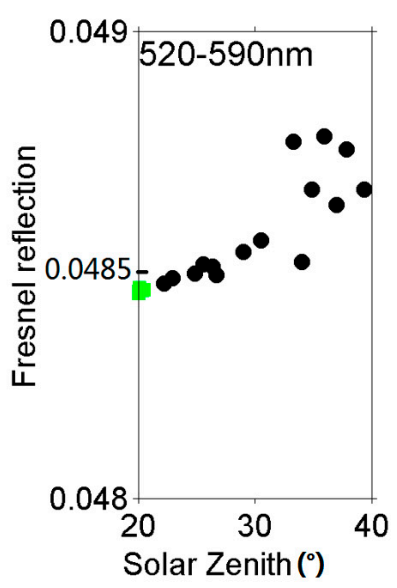

(b)

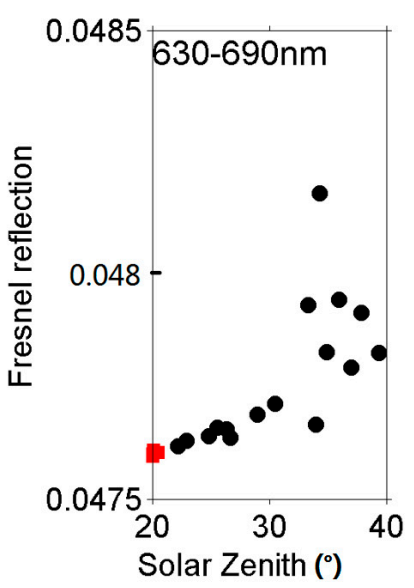

(c)

Figure 8. Fresnel reflection coefficients of 22 samples: (a) 450-520 nm; (b) 520-590 nm; (c) 630-690 nm (colored squares represent samples with solar zenith angles between 19 and $22^{\circ}$ ).

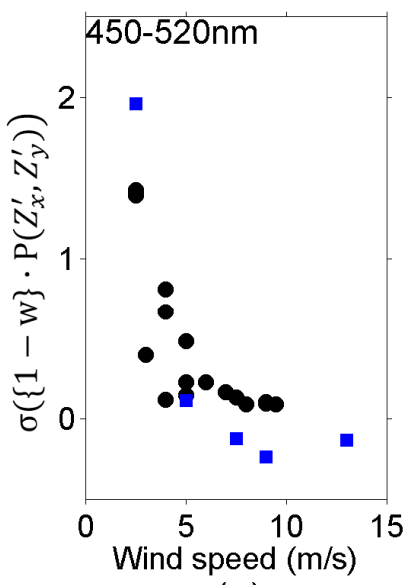

(a)

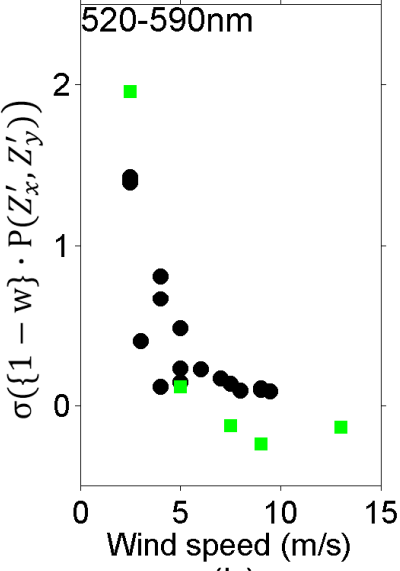

(b)

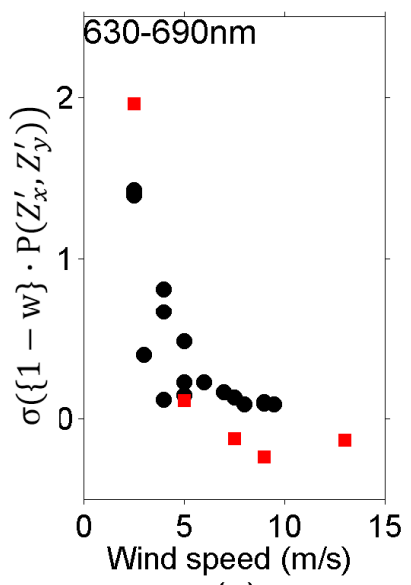

(c)

Figure 9. $\{1-W\} \cdot P\left(Z_{x}^{\prime}, Z_{y}^{\prime}\right)$ variations with a wind speed that changed $\pm 2 \mathrm{~m} / \mathrm{s}$ in the 22 samples: (a) 450-520 nm, (b) 520-590 nm, and (c) 630-690 nm (colored squares represent samples with solar zenith angles between 19 and $22^{\circ}$ ).

According to the uncertainty analysis of AOD, the samples with a SZ of $19-22^{\circ}$ (Sample ID 5, 6, $7,10,11$ and 19) have small uncertainties. Meanwhile, as shown in Figures 7 and 8, when the $V$ is larger than $5 \mathrm{~m} / \mathrm{s}$, the smaller SZ value samples have smaller variations in their Fresnel's reflection coefficients and $\{1-W\} \cdot P\left(Z_{x}^{\prime}, Z_{y}^{\prime}\right)$ induced by the $V$ errors (colored squares in Figure 9, except for Samples 6 and 9 which both have a $V$ of less than $5 \mathrm{~m} / \mathrm{s}$ ). Considering a $V$ of $5-13 \mathrm{~m} / \mathrm{s}$, Samples 5, 7, 10 , and 11 are selected. Figure 10 shows that the $\sigma_{i}$ of these 4 samples reaches its minimum among 22 samples. Therefore, selecting the best samples should consider two conditions of SZ (19-22 $)$ and $V$ $(5-13 \mathrm{~m} / \mathrm{s})$, based on the uncertainty analysis of 22 calibration samples. 


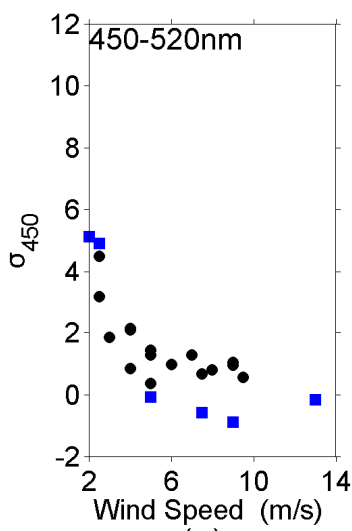

(a)

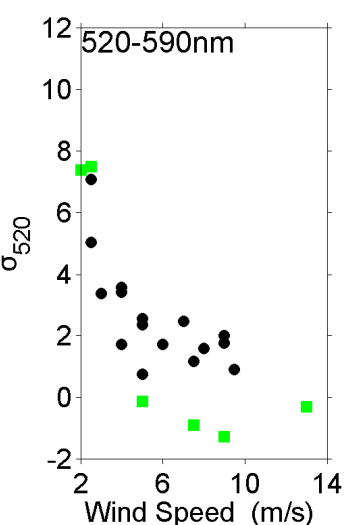

(b)

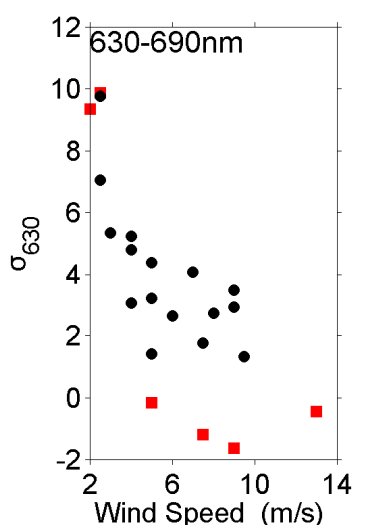

(c)

Figure 10. $\sigma_{i}$ (calibration coefficients uncertainty) with a wind speed that changed $\pm 2 \mathrm{~m} / \mathrm{s}$ in the 22 samples: (a) 450-520 nm; (b) 520-590 nm and (c) 630-690 nm (colored squares represent samples with solar zenith angles between 19 and $22^{\circ}$ ).

\subsubsection{Simulation Analysis}

The analysis in Section 4.5.1 is based on 22 samples, with an SZ and $V$ range of $19-40^{\circ}$ and $2-13 \mathrm{~m} / \mathrm{s}$, respectively. An analysis with more general conditions is conducted using the 6S RTM (input parameters in Table 7) in order to study the influence of wind speed and geometric conditions. Under certain wind and geometric conditions, the TOA reflectance is insensitive to the wind speed error and presents stable calibration results.

Table 7. 6S input parameters for the simulation of wind speed and solar zenith angles.

\begin{tabular}{ccccc}
\hline & Solar Zenith Angle & View Zenith Angle & Relative Azimuth Angle & Wind Speed \\
\hline Range & $0-70^{\circ}$ & $10^{\circ}$ & $0-180^{\circ}$ & $0-15 \mathrm{~m} / \mathrm{s}$ \\
Step & $5^{\circ}$ & & $60^{\circ}$ & $1 \mathrm{~m} / \mathrm{s}$ \\
\hline
\end{tabular}

Figure 11 shows that there exist two conditions in which the calibration uncertainty is small. (1) When the SZ is large $\left(>60^{\circ}\right)$, the Rayleigh scattering of gas molecules contributes more to the TOA signals and the $V$ error brings little uncertainty. This situation is consistent with Vermote et al. [22] and Dilligeard et al. [28]. (2) However, when the SZ is small $\left(<30^{\circ}\right)$, a larger $V$ leads to little uncertainty. In this paper, the SZs of all the samples are not large enough so that the larger $V$ is good for Rayleigh scattering calibration. Therefore, Figure 10 (small SZ and big $V$ ) is consistent with the second condition in Figure 11.

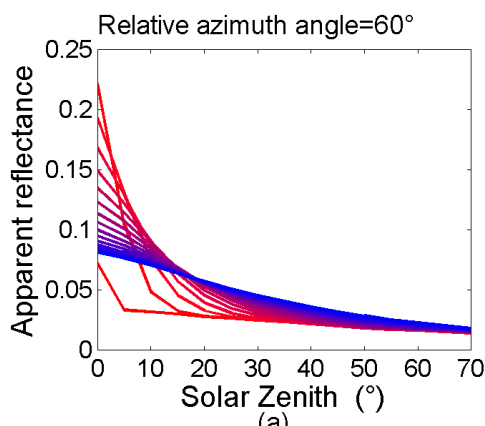

(a)

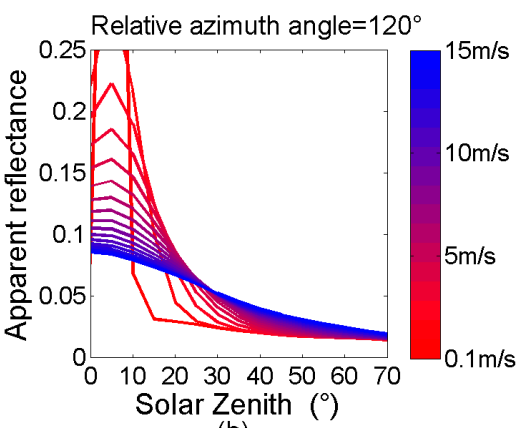

(b)

Figure 11. TOA (Top Of the atmosphere) reflectance $(630-690 \mathrm{~nm}$ ) varying with solar zenith angle and wind speed, calculated at a relative azimuth angle of: (a) $60^{\circ}$ and (b) $120^{\circ}$. The view zenith angle is $10^{\circ}$ in both cases (a sun glint reflectance greater than 0.25 is not shown). 


\section{Final Results and Total Uncertainty}

According to the uncertainty analysis, the calibration coefficient uncertainty induced by seawater salinity, chlorophyll concentration and ozone is not a large value. The uncertainty of the AOD should be considered, but its selection rule is not clear when AOD is not larger than 0.1. For selecting from the 22 samples, the sun zenith angle and wind speed was set at a range of $19-22^{\circ}$ and $5-13 \mathrm{~m} / \mathrm{s}$, respectively. Under these conditions, 4 samples (ID: 5, 7, 10, and 11) were selected to give the mean calibration values of 0.1749 (blue), 0.1618 (green), and 0.1374 (red), while the largest deviation ratios were $3.89 \%$ (blue), 3.59\% (green), and $4.8 \%$ (red). The calibration coefficients for each sample are listed in Table 8 . The relative deviations between the final results of Rayleigh scattering calibration and the Dun Huang field calibration are $-1.69 \%$ (blue), $1.83 \%$ (green), and $0.79 \%$ (red). Compared with the primary result $(-1.35 \%$ (blue), $3.52 \%$ (green), and $-2.45 \%$ (red)), the blue band has a slightly larger deviation, while the green and red bands results become much more stable.

Table 8. $A_{i}$ (Calibration coefficients) of Samples 5, 7, 10, and 11.

\begin{tabular}{|c|c|c|c|}
\hline Sample ID $\quad$ Band & $450-520 \mathrm{~nm}$ & $520-590 \mathrm{~nm}$ & $630-690 \mathrm{~nm}$ \\
\hline 5 & 0.1817 & 0.1656 & 0.1425 \\
\hline 7 & 0.1713 & 0.1589 & 0.1335 \\
\hline 10 & 0.1701 & 0.156 & 0.1308 \\
\hline 11 & 0.1764 & 0.1668 & 0.1429 \\
\hline Mean (ACC) & 0.1749 & 0.1618 & 0.1374 \\
\hline Largest deviation (LD) & 0.0068 & 0.0058 & 0.0066 \\
\hline Largest deviation ratio (LDR) & $3.89 \%$ & $3.59 \%$ & $4.8 \%$ \\
\hline
\end{tabular}

The averaged calibration coefficient uncertainties of the selected four samples are listed in Table 9. The uncertainty for each factor (ozone, AOD, sea water salinity, chlorophyll concentration and wind speed) is lower than that of 22 samples. The total uncertainty is the square root of the sum of the squares of the uncertainties from all five factors. The total uncertainties in Table 9 are $2.44 \%$ (blue), $3.86 \%$ (green), and $4.63 \%$ (red). As the Dun Huang field calibration accuracy is 5.3\% [31], the Rayleigh scattering method becomes comparably even more accurate after sample selection.

Table 9. $\sigma_{\mathrm{i}}$ (Calibration coefficient uncertainties for Samples 5, 7, 10, and 11) from atmosphere and marine parameters (total uncertainty is the square root of the sum of the squares of the uncertainties from all five factors).

\begin{tabular}{|c|c|c|c|}
\hline Factor Band & $\sigma_{i} 450-520 \mathrm{~nm}$ & $\sigma_{i} 520-590 \mathrm{~nm}$ & $\sigma_{i} 630-690 \mathrm{~nm}$ \\
\hline Ozone & $0.39 \%$ & $1.56 \%$ & $0.61 \%$ \\
\hline $\mathrm{AOD}$ & $0.87 \%$ & $0.98 \%$ & $1.03 \%$ \\
\hline Salinity & $0.03 \%$ & $0.04 \%$ & $0.06 \%$ \\
\hline Chlorophyll & $0.17 \%$ & $0.3 \%$ & $0.06 \%$ \\
\hline Wind speed & $2.24 \%$ & $3.39 \%$ & $4.37 \%$ \\
\hline Total uncertainty & $2.44 \%$ & $3.86 \%$ & $4.63 \%$ \\
\hline
\end{tabular}

Moreover, the systematic calibration uncertainty induced by the RTM should be considered. The choice of the RTM may introduce an uncertainty less than $1 \%$, although the errors are largely counterbalanced [39]. In this paper, we only considered the main uncertainty induced by measurements. Therefore, the absolute calibration uncertainty should be a little bigger than the total uncertainties in Table 9. 


\section{Conclusions}

The absolute radiometric calibration is the key factor to determine the accuracy of the optical remote-sensing product. The WFV payload onboard the GF-1 satellite was calibrated with the Rayleigh scattering method for its visible bands. Based on 31 ocean images of GF-1/WFV, 22 targets were selected for the Rayleigh scattering calibration. Through calibration coefficients uncertainty analysis of related atmosphere and marine factors, the samples were selected with strict rules. According to the two fixed conditions of sun zenith angle $\left(19-22^{\circ}\right)$ and wind speed $(5-13 \mathrm{~m} / \mathrm{s})$, four samples were selected. The mean values for the calibration coefficients are 0.1749 (blue), 0.1618 (green), and 0.1374 (red), with a maximum uncertainty of less than $4.63 \%$ (caused by measurements only). This shows comparable accuracy with the Dun Huang field calibration.

In order to get more accurate results, the image processing and sample selection rules are as follows:

\section{(1) Target Scale}

Due to the characteristics of light and dark surfaces distinguished in a high spatial resolution sensor image, the averaging method for reducing the scale is used to eliminate the influence of the wave surface. The spatial resolution of a WFV image is $16 \mathrm{~m}$ and $3-5 \mathrm{~km}$ is suitable for scale selection, which ensures accuracy of the surface radiation calculation.

\section{(2) Quality Recommendations}

The coefficient uncertainty induced by wind speed shows the most obvious variations among all atmospheric and oceanic factors. Considering the simulation results $( \pm 2 \mathrm{~m} / \mathrm{s}$ for wind speed error), the selection rule for optimal targets concluded from TOA reflectance simulations needs specifying a combination of geometry conditions and wind speed. Therefore, the sample selection standard for quality control could be concluded as follows.

Samples with a large sun zenith angle $\left(>60^{\circ}\right)$ represent accurate calibration results, while simulation analysis indicates that more samples can be selected with a small sun zenith angle and fast wind speed. According to the simulation and sample uncertainty analysis, the sun zenith angle of $19-22^{\circ}$ and a wind speed of $5-13 \mathrm{~m} / \mathrm{s}$ were chosen for the selection rule. The selected samples performed with a small coefficient of uncertainty of $2.44 \%$ (blue), $3.86 \%$ (green), and $4.63 \%$ (red).

Although the sample number in this calibration campaign is limited and not in accordance with the original selection rule of a large sun zenith angle, after using the TOA reflectance simulation with varying sun zenith angle and wind speed, the sample selecting rules were specified and the calibration accuracy was improved by using the above sample selection rule, becoming slightly better than the field calibration. Furthermore, high spatial resolution satellites could be arranged to acquire ocean images in a short time (possibly one day) with multi-level gains and exposure time settings. Following this, the multiple calibrations will be finished quickly and easily. As for the calibration of the near-infrared bands of GF-1/WFV, sun glint and cloud calibration [19] can be implemented by transferring the Rayleigh calibration result of the visible bands. As some in-situ measurements of the atmospheric and oceanic parameters can be obtained from some stable sites, the Rayleigh scattering calibration could be an effective method for the operational in-flight calibration of high-resolution terrestrial satellites.

Acknowledgments: This work was supported by the National Natural Science Foundation of China (Grant No.: 41501399, No.: 41401424) and the Open Fund of Key Laboratory of Optical Calibration and Characterization, Chinese Academy of Sciences (Grant No.: 2016JJ-3).

Author Contributions: All authors conceived and designed the study. Xingfeng Chen and Zhengqiang Li performed the calibration method and prepared the paper. Jin Xing, Li Liu, and Qiaoyan Fu preprocessed the satellite images and provided validation data. Xiaodong Mei processed the data and analyzed uncertainty. Yisong Xie and Bangyu Ge provided useful advice for uncertainty analysis. Hua Xu and Kaitao Li provided technical guidance and revised the paper.

Conflicts of Interest: The authors declare no conflict of interest. 


\section{References}

1. Wu, M.Q.; Huang, W.J.; Niu, Z.; Wang, C.Y. Combining HJ CCD, GF-1 WFV and MODIS data to generate daily high spatial resolution synthetic data for environmental process monitoring. Int. J. Environ. Res. Public Health 2015, 12, 9920-9937. [CrossRef] [PubMed]

2. Gao, H.L.; Gu, X.F.; Yu, T.; Sun, Y.; Liu, Q.Y. Cross-calibration of GF-1 PMS sensor with Landsat 8 OLI and terra MODIS. IEEE Trans. Geosci. Remote Sens. 2016, 54, 4847-4854. [CrossRef]

3. Xiong, X.X.; Sun, J.Q.; Xie, X.B.; Barnes, W.L.; Salomonson, V.V. On-orbit calibration and performance of aqua MODIS reflective solar bands. IEEE Trans. Geosci. Remote Sens. 2010, 48, 535-546. [CrossRef]

4. Calibration Coefficients of the Chinese Land Observation Satellites. Available online: http://www.cresda. com/CN/Downloads/dbcs/index.shtml (accessed on 22 May 2017).

5. Yang, A.X.; Zhong, B.; Lv, W.B.; Wu, S.L.; Liu, Q.H. Cross-calibration of GF-1/WFV over a desert site using landsat-8/OLI imagery and ZY-3/TLC data. Remote Sens. 2015, 7, 10763-10787. [CrossRef]

6. Liu, L.; Shi, T.; Fu, Q.; Han, Q. Spectral band adjustment factors for cross calibration of GF-1 WFV and terra MODIS. In Proceedings of the IEEE Geoscience and Remote Sensing Symposium (IGARSS 2015), Milan, Italy, 26-31 July 2015; pp. 2119-2122.

7. Liu, L.; Shi, T.; Han, Q.; Zhang, X. Multitemporal cross-calibration of GF-1 WFV and terra MODIS reflective solar bands. Proc. SPIE 2014, 9298. [CrossRef]

8. Dinguirard, M.; Slater, P.N. Calibration of space-multispectral imaging sensors: A review. Remote Sens. Environ. 1999, 68, 194-205. [CrossRef]

9. Slater, P.N.; Biggar, S.F.; Holm, R.G.; Jackson, R.D.; Mao, Y.; Moran, M.S.; Palmer, J.M.; Yuan, B. Reflectance-based and radiance-based methods for the in-flight absolute calibration of multispectral sensors. Remote Sens. Environ. 1987, 22, 11-37. [CrossRef]

10. Biggar, S.F.; Thome, K.J.; Wisniewski, W. Vicarious radiometric calibration of EO-1 sensors by reference to high-reflectance ground targets. IEEE Trans. Geosci. Remote Sens. 2003, 41, 1174-1179. [CrossRef]

11. Sun, L.; Hu, X.Q.; Guo, M.H.; Xu, N. Multisite calibration tracking for FY-3A MERSI solar bands. IEEE Trans. Geosci. Remote Sens. 2012, 50, 4929-4942. [CrossRef]

12. Cabot, F.; Hagolle, O.; Henry, P. Relative and multitemporal calibration of AVHRR, seawifs, and vegetation using polder characterization of desert sites. In Proceedings of the IEEE Geoscience and Remote Sensing Symposium 2000 (IGARSS 2000), Honolulu, HI, USA, 27-28 July 2000; pp. 2188-2190.

13. De Vries, C.; Danaher, T.; Denham, R.; Scarth, P.; Phinn, S. An operational radiometric calibration procedure for the landsat sensors based on pseudo-invariant target sites. Remote Sens. Environ. 2007, 107, 414-429. [CrossRef]

14. Kieffer, H.H.; Stone, T.C. The spectral irradiance of the moon. Astron. J. 2005, 129, 2887-2901. [CrossRef]

15. Doelling, D.R.; Nguyen, L.; Minnis, P. On the use of deep convective clouds to calibrate AVHRR data. Proc. SPIE 2004, 5542. [CrossRef]

16. Meygret, A.; Briottet, X.; Henry, P.J.; Hagolle, O. In Calibration of SPOT4 HRVIR and Vegetation Cameras over Rayleigh Scattering. Proc. SPIE 2000, 4135. [CrossRef]

17. Fraser, R.S.; Kaufman, Y.J. Calibration of satellite sensors after launch. Appl. Opt. 1986, 25, 1177-1185. [CrossRef] [PubMed]

18. Vermote, E.; Santer, R.; Deschamps, P.Y.; Herman, M. In-flight calibration of large field of view sensors at short wavelengths using rayleigh-scattering. Int. J. Remote Sens. 1992, 13, 3409-3429. [CrossRef]

19. Hagolle, O.; Goloub, P.; Deschamps, P.Y.; Cosnefroy, H.; Briottet, X.; Bailleul, T.; Nicolas, J.M.; Parol, F.; Lafrance, B.; Herman, M. Results of polder in-flight calibration. IEEE Trans. Geosci. Remote Sens. 1999, 37, 1550-1566. [CrossRef]

20. Briottet, X.; Dilligeard, E.; Santer, R.; Deuze, J.L. Vegetation calibration of the blue and red channels using rayleigh scattering over open oceans. Int. Soc. Opt. Photonics 1997, 3221, 318-325.

21. Vermote, E.; Kaufman, Y.J. Absolute calibration of avhrr visible and near-infrared channels using ocean and cloud views. Int. J. Remote Sens. 1995, 16, 2317-2340. [CrossRef]

22. Vermote, E.F.; Tanre, D.; Deuze, J.L.; Herman, M.; Morcrette, J.J. Second simulation of the satellite signal in the solar spectrum, 6S: An overview. IEEE Trans. Geosci. Remote Sens. 1997, 35, 675-686. [CrossRef] 
23. Lee, J.; Kim, J.; Yang, P.; Hsu, N.C. Improvement of aerosol optical depth retrieval from MODIS spectral reflectance over the global ocean using new aerosol models archived from aeronet inversion data and tri-axial ellipsoidal dust database. Atmos. Chem. Phys. 2012, 12, 7087-7102. [CrossRef]

24. McPeters, R.; Bhartia, P.; Krueger, A.; Herman, J.; Wellemeyer, C.; Seftor, C.; Jaross, G.; Torres, O.; Moy, L.; Labow, G. Earth Probe Total Ozone Mapping Spectrometer (TOMS) Data Product User's Guide. Available online: https:/ / ozoneaq.gsfc.nasa.gov/media/docs/epusrguide.pdf (accessed on 22 May 2017).

25. Xue, Y.; Wen, C.; Yang, X.; Behringer, D.; Kumar, A.; Vecchi, G.; Rosati, A.; Gudgel, R. Evaluation of tropical pacific observing systems using NCEP and GFDL ocean data assimilation systems. Clim. Dyn. 2015. [CrossRef]

26. Carder, K.L.; Chen, F.R.; Cannizzaro, J.P.; Campbell, J.W.; Mitchell, B.G. Performance of the MODIS semi-analytical ocean color algorithm for chlorophyll-a. Adv. Space Res. 2004, 33, 1152-1159. [CrossRef]

27. Uppala, S.M.; Kallberg, P.W.; Simmons, A.J.; Andrae, U.; Bechtold, V.D.; Fiorino, M.; Gibson, J.K.; Haseler, J.; Hernandez, A.; Kelly, G.A.; et al. The ERA-40 re-analysis. Q. J. R. Meteorol. Soc. 2005, 131, $2961-3012$. [CrossRef]

28. Dilligeard, E.; Briottet, X.; Deuze, J.L.; Santer, R.P. Spot calibration of blue and green channels using rayleigh scattering over clear oceans. Proc. SPIE 1997, 2957. [CrossRef]

29. Frouin, R. In-Flight Calibration of Satellite Ocean-Colour Sensors. Available online: http://genius.ucsd.edu/ Public/IOCCG_Calibration_Report_27Jan13.pdf (accessed on 22 May 2017).

30. Kotchenova, S.Y.; Vermote, E.F.; Matarrese, R.; Klemm, F.J. Validation of a vector version of the 6 s radiative transfer code for atmospheric correction of satellite data. Part I: Path radiance. Appl. Opt. 2006, 45, 6762-6774. [CrossRef] [PubMed]

31. Han, Q.J.; FU, Q.Y.; Zhang, X.W.; Liu, L. High-frequency radiometric calibration for wide field-of-view sensor of GF-1 satellite. Opt. Precis. Eng. 2014, 22, 1707-1714.

32. Fougnie, B.; Henry, P.; Morel, A.; Antoine, D.; Montagner, F. Identification and Characterization of Stable Homogeneous Oceanic Zones: Climatology and Impact on In-Flight Calibration of Space Sensor over Rayleigh Scattering. Available online: http://omtab.obs-vlfr.fr/fichiers_PDF/Fougnie_et_al_OOXVI_02.pdf (accessed on 22 May 2017).

33. Fougnie, B.; Llido, J.; Gross-Colzy, L.; Henry, P.; Blumstein, D. Climatology of oceanic zones suitable for in-flight calibration of space sensors. Proc. SPIE 2010, 7807. [CrossRef]

34. Koepke, P. Effective reflectance of oceanic whitecaps. Appl. Opt. 1984, 23, 1816-1824. [CrossRef] [PubMed]

35. Monahan, E.C.; Muircheartaigh, I.O. Optimal power-law description of oceanic whitecap coverage dependence on wind-speed. J. Phys. Oceanogr. 1980, 10, 2094-2099. [CrossRef]

36. Cox, C.; Munk, W. Measurement of the roughness of the sea surface from photographs of the suns glitter. JOSA 1954, 44, 838-850. [CrossRef]

37. Cox, C.; Munk, W. Thereforeme problems in optical oceanography. J. Mar. Res. 1955, 14, 63-78.

38. Cox, C.; Munk, W. Statistics of the sea surface derived from sun glitter. J. Mar. Res. 1954, 13, 198-227.

39. Slater, P.N.; Biggar, S.F.; Thome, K.J.; Gellman, D.I.; Spyak, P.R. The in-flight radiometric calibration of aster by reference to well-characterized scenes. Int. Soc. Opt. Photonics 1995, 2317, 49-60.

(C) 2017 by the authors. Licensee MDPI, Basel, Switzerland. This article is an open access article distributed under the terms and conditions of the Creative Commons Attribution (CC BY) license (http:// creativecommons.org/licenses/by/4.0/). 